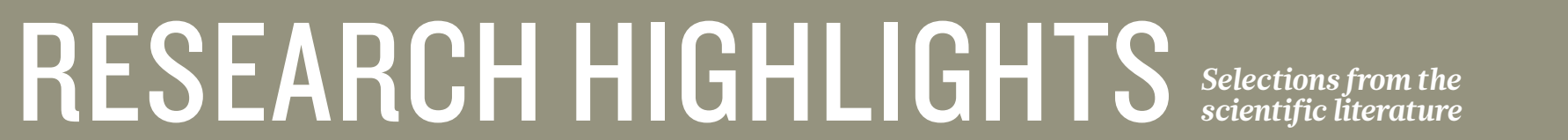

APPLIED PHYSICS

\section{A low-power light amplifier}

A semiconductor device can amplify the tiny signal from incoming photons using much less power and creating much less noise than current methods.

Previously, converting a signal from photons into a usable electrical signal required the use of two devices running at relatively high voltages - one device to convert the photon to an electrical signal and another to amplify it.

Yu-Hwa Lo at the University of California, San Diego, and his colleagues exploited a different amplification mechanism to consolidate the process into a single device. By engineering a special junction between layers of silicon with two different kinds of impurities, the team amplified the light signals by more than a factor of 4,000 and induced 30 times less noise in the signal than conventional methods.

Appl. Phys. Lett. 107, 053505 (2015)

AGRICULTURE
Pig-farming
history traced

Domesticated pigs (pictured) routinely interbred with wild boars - contrary to common assumptions that humans kept their animals isolated.

Humans domesticated pigs from wild boars

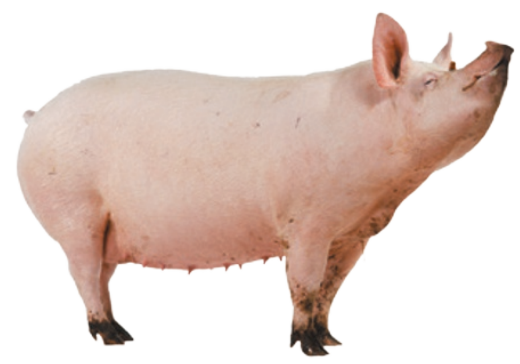

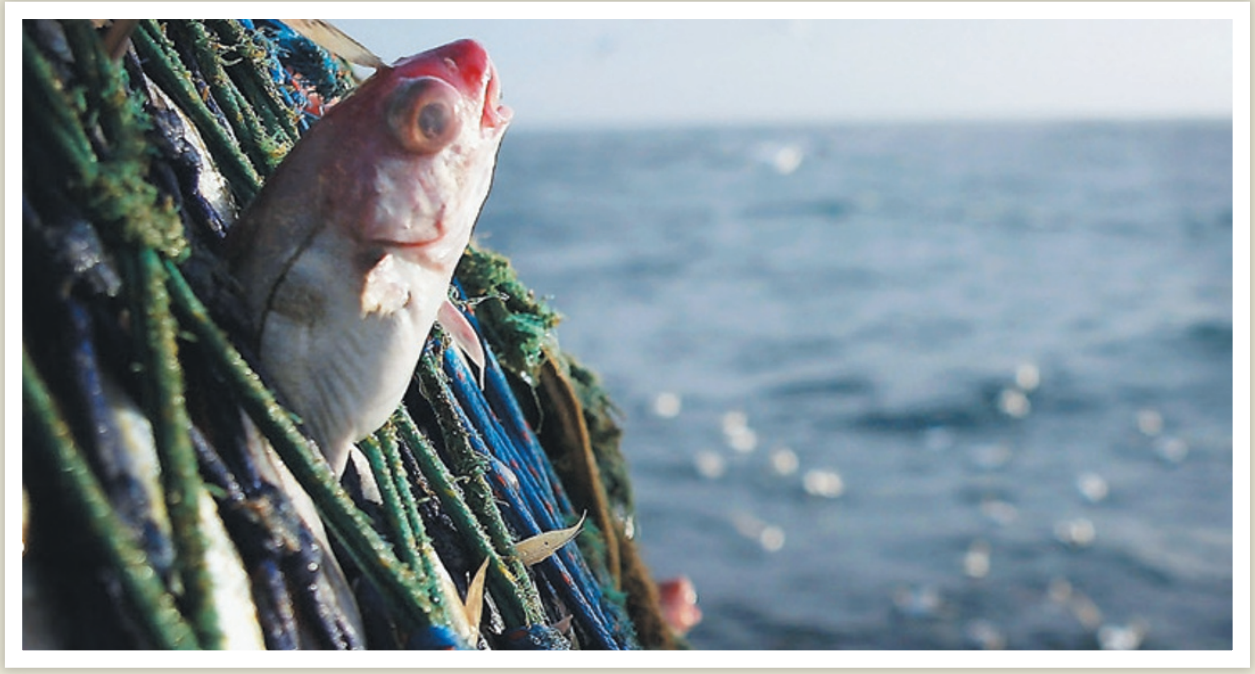

\section{FISHERIES}

\section{Finding a limit for deep-sea fishing}

The negative ecological impact of trawling for fish at depths of more than 600 metres outweighs the commercial benefits.

Deep-sea fish are particularly vulnerable to overfishing because populations grow slowly. This has led to calls for a maximum depth for trawling, but it has not been clear what that limit should be. By examining species from scientific surveys of the northeast Atlantic over 35 years, Jo Clarke at the University of Glasgow, UK, and her colleagues found that the proportion of caught fish with no commercial value increased significantly below 600 metres.

Although this evidence supports a 600metre depth limit in the northeast Atlantic, its relevance to other fishing areas is untested. Curr. Biol. http://doi.org/66n (2015)

For more on this story, see go.nature.com/yjedl3 independently in Anatolia (modern-day Turkey) and East Asia around 9,000 years ago. To learn about pigpopulation histories, a team led by Laurent Frantz at the University of Oxford, UK, analysed the genomes of more than 600 modern pigs and wild boars. After initial domestication in Anatolia, the ancestors of European pigs interbred with at least two different populations of wild boars that ranged between Europe and Anatolia. Pigs from East Asia seem to have interbred with local boars too. Despite this wild mixing, domestic pig genomes show signs of positive selection at regions that include genes involved in behaviour and anatomy.

The researchers propose that ancient herders repeatedly selected pigs with useful traits, counteracting the effects of the wild boar genes.

Nature Genet. http://dx.doi. org/10.1038/ng.3394 (2015)

\section{ECOLOGY \\ Coral foe becomes a friend}

Seaweed often inhibits the growth of corals, but it can help them when they are faced with a coral-eating starfish.

Seaweed can suppress coral growth by shading it from sunlight and by releasing toxic chemicals. Cody Clements and Mark Hay at the Georgia
Institute of Technology in Atlanta surrounded branches of a coral species (Montipora hispida) near Fiji with varying numbers of fronds of a common brown alga (Sargassum polycystum). After 4 months, they found that the growth rate of coral branches unencumbered by the seaweed was 2.7 times higher than corals with 8 surrounding fronds (the highest number tested).

However, coral branches surrounded by four or more seaweed fronds were rarely attacked by the crown-ofthorns starfish (Acanthaster planci), which devoured all the exposed corals.

Proc. R. Soc. B 282, 20150714

(2015) 